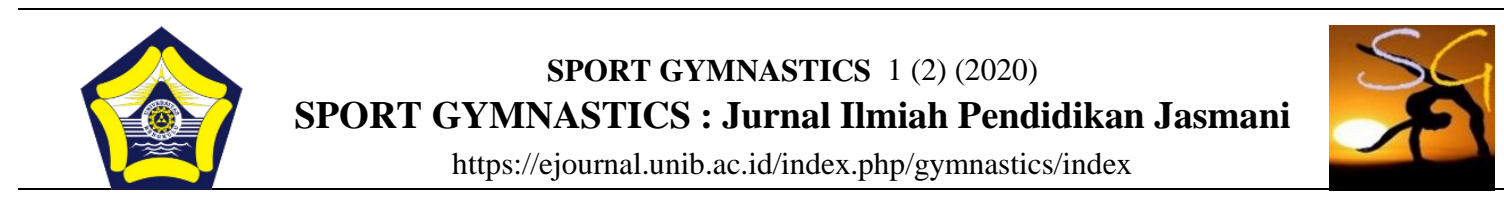

\title{
MOTIVASI DAN SARANA PRASARANA LATIHAN ATLET PROVINSI BENGKULU MENUJU PON XX PAPUA
}

Desti Dui Nilasari.M1 ${ }^{1}$, Syafrial ${ }^{2}$, Bogy Restu Ilahi ${ }^{3}$

${ }^{123}$ Prodi Pendidikan Jasmani, FKIP, Universitas Bengkulu, Kota Bengkulu , Indonesia

\begin{tabular}{l}
\hline Info Artikel \\
\hline Sejarah Artikel: \\
Diterima Oktober 2020 \\
Direvisi Oktober 2020 \\
Diterima Oktober 2020 \\
Tersedia online Oktober 2020 \\
\hline Kata kunci: \\
Motivasi, Sarana dan Prasarana, \\
\& PON \\
\hline
\end{tabular}

\begin{abstract}
Abstrak
Penelitian ini bertujuan untuk mengetahui bagaimana Motivasi dan Sarana Prasarana Latihan Atlet Provinsi Bengkulu Menuju PON XX Papua. Jenis penelitian ini adalah penelitian deskriptif kualitatif. Subjek dalam penelitian ini adalah seluruh cabang olahraga Provinsi Bengkulu menuju PON XX Papua dengan jumlah atlet 83 orang dan pelatih 16 orang. Instrumen dan teknik pengumpulan data yang digunakan dalam penelitian ini adalah angket dan member check. Teknik analisis data yang digunakan adalah analisis deskriptif dengan presentase. Hasil penelitian menyatakan bahwa motivasi latihan atlet sebesar $85,40 \%$ dengan katagori sangat baik, dan sarana prasarana latihan atlet 1 cabang olahraga Panjat Tebing sebesar 6,25\% dengan katagori sangat baik, 9 cabang olahraga, Voli, Bulu Tangkis, Tenis Lapangan, Silat, Tinju, Gulat, Karate, Selam, PABBSI sebesar 56,25\% dengan katagori baik dan 6 cabang olahraga Sepak bola, Muaythai, Kempo, Atletik, Renang, Billiard sebesar 37,5\% dengan katagori cukup. Berdasarkan hasil penelitian dapat disimpulkan bahwa motivasi latihan atlet dengan kategori sangat baik dan sarana prasarana dengan kategori baik.
\end{abstract}

\begin{abstract}
Abstrack
The purpose of this research was to find out how to Motivate and Training Facilities of Bengkulu Province Athletes for PON XX Papua. This type of research is a qualitative descriptive study. The subjects in this study was all Bengkulu Province sports branches for PON XX Papua with 83 athletes and 16 trainers. The instruments and data collection techniques that $\mathrm{i}$ used in this study was questionnaire and member check. The data analysis technique that $\mathrm{i}$ used was descriptive analysis with a percentage. The result of this research declared that athlete training motivation is 85,40 $\%$ with the very well category and facilties-infrastructure training atlhete 1 branch of rock climbing was $6,25 \%$ with the very well category 9 branch of volley ball, badminton, tennis, silat, boxing, wrestling, karate, diving PABBSI is $56,25 \%$ with good category
\end{abstract}


and 6 branch football, muay thai, kempo, Athletic, swimming, and biliard is $37,5 \%$ with the medium category based on result of this research can be concluded that motivation atlhete with very well category and facilities-infrasturcture with good category.

Alamat yang sesuai: Surabaya Permai I, Bengkulu

Email yang sesuai: destiduinilasari28@gmail.com

\section{PENDAHULUAN}

Olahraga adalah kegiatan yang dapat mendorong, mengembangkan dan membina potensi-potensi jasmani dan rohani. Olahraga dapat di katakan sebagai suatu permainan, perlombaan dan pertandingan. Olahraga juga berkaitan dengan pendidikan jasmani dan rekreasi, karena dalam penetapan batasan dalam pendidikan jasmani harus pula dipertimbangkan kaitannya dengan permainan. dan olahraga. Selain untuk pendidikan, olahraga juga dapat digunakan sebagai kegiatan rekreasi untuk menghilangkan stres maupun jenuh terhadap suatu pekerjaan. Olahraga yang teratur akan membantu menjaga kebugaran tubuh dan menyempurnakan penampilan.

Olahraga Rekreasi adalah olahraga yang dilakukan oleh masyarakat dengan kegemaran dan kemampuan yang tumbuh dan berkembang sesuai dengan kondisi dan nilai budaya masyarakat setempat untuk kesehatan, kebugaran, dan kegembiraan. Serta olahraga prestasi adalah olahraga yang membina dan mengembangkan olahragawan secara terencana, berjenjang, dan berkelanjutan melalui kompetisi untuk mencapai prestasi dengan dukungan ilmu pengetahuan dan teknologi keolahragaan.

Pekan Olahraga Nasional (PON) sebagai gelaran olahraga di Indonesia untuk mencari bibit-bibit atlet berbakat disetiap cabang olahraga di seluruh penjuru Negeri, PON direncanakan akan berlangsung pada tahun 2020 tepatnya pada tanggal 20 Oktober hingga 2 November yang akan di selenggarakan di Provinsi Papua, akan tetapi di undur pada tahun 2021 dikarenakan ada bencana besar yang di alami Indonesia maupun dunia yaitu Pademi Covid-19, maka dari itu PON di undur.

Masing-masing daerah sudah mempersiapkan atlet untuk meraih kemenangan dalam pekan olahraga nasional, khususnya di Provinsi Bengkulu. Bicara mengenai prestasi olahraga di provinsi Bengkulu, dari dulu memang provinsi Bengkulu tidak pernah bisa berbicara banyak karena masih sangat kurangnya prestasi olahraga di Provinsi Bengkulu, akan tetapi di ajang PORWIL dan PRA PON 2019 Bengkulu bisa membuktikan bawah banyak cabang olahraga yang bisa lolos ke tingkat Pekan Olahraga Nasional PON baik itu di cabang olahraga beregu maupun cabang olahraga individu.

Salah satu faktor dalam peserta berbagai cabang Olahraga Provinsi Bengkulu adalah motivasi berprestasi. Menurut teori motivasi berprestasi, kebutuhan prestasi adalah kecendrungan untuk mencapai keberhasilan atau tujuan, dan melakukan kegiatan yang mengarah pada kesuksesan atau kegagalan. Motivasi berprestasi merupakan keiginan untuk memperoleh keberhasilan dan berpartisipasi aktif didalam suatu kegiatan. 
Sarana dan prasarana olahraga yaitu suatu yang dapat digunakan dan di manfaatkan dalam pelaksanaan kegiatan olahraga. Sarana di dalam olahraga diartikan sesuatu yang digunakan dan dimanfaatkan dalam pelaksanaan kegiatan olahraga atau penjas, sarana terbagi menjadi dua yaitu sarana peralatan dan sarana perlengkapan. Prasarana adalah suatu yang mempermudah atau mempelancar tugas dan memiliki sifat yang relatif permanen.

Sarana dan prasarana masih kurang di perhatikan dan dikelola dengan baik, misalnya seperti sport center atau pun wisma atlet, terutama peralatan dasar latihan para atlet. Masing-masing cabang olahraga yang Lolos ke tahap pekan Olahraga Nasional (PON), harus memiliki sarana dan prasarana yang memadai dan lengkap saat latihan sesuai dengan cabang olahraga masing-masing misalnya seperti olahraga sepakbola, yang memerlukan lapangan yang bagus dan standar seperti stadion agar proses latihan bisa berjalan dengan baik dan nyaman begitu pun di cabang olahraga lainnya. Belum di ketahuinya bagaimana motivasi atlet dan prosedur pemeliharaan dari sarana dan prasarana olahraga yang baik oleh pengelola dan sarana prasarana sangat berpengaruh dalam pencapaian tujuan dari suksesnya atlet di dalam pertandingan ataupun perlombaan di ajang Pekan Olahraga Nasional (PON) XX Papua.

Berdasarkan uraian dan penjelasan dari latar belakang tersebut, maka peneliti tertarik untuk melakukan penelitian tentang " motivasi dan sarana prasarana latihan Atlet Provinsi Bengkulu menuju PON XX Papua " penelitian ini dilakukan untuk mengetahui bagaimana motivasi atlet dalam latihan dan bagaimana sarana dan prasarana Latihan Atlet Provinsi Bengkulu menuju PON XX Papua.

\section{METODE PENELITIAN}

Penelitian merupakan kegiatan sistematik yang dimaksudkan untuk menambah pengetahuan baru atas pengetahuan yang sudah ada. Dengan adanya cara yang dapat dikomunikasikan dan dapat dinilai kembali. Sebelum melakukan penelitian dibutuhkan terlebih dahulu desain penelitian agar nantinya penelitian dapat terarah dan berjalan secara sistematis. Desain penelitian ini adalah penelitian deskriptif kualitatif dengan metode survei yang menggunakan angket. Menurut Arikunto (2016:78) "penelitian deskriptif merupakan penelitian non hipotesis tetapi hanya menggambarkan seperti apa adanya tentang suatu keadaan".

Proses pengumpulan data dilakukan dengan cara memberikan angket kepada responden yang dalam hal ini adalah Atlet Provinsi Bengkulu yang mengikuti PON XX Papua. Sebelum memulai pengisian, peneliti telah memberikan penjelasan kepada responden mengenai tata cara pengisian biodata maupun menjawab butir soal pertanyaan. Selanjutnya Peneliti menbagikan angket kepada responden untuk di isi. Peneliti memberikan waktu pengerjaan kepada responden Selama 20 menit dengan jumlah total pertanyaan kuisioner (angket) sebanyak 30 butir soal. Setelah selesai menjawab semua soal pernyataan kemudian peneliti mengumpulkan angket yang telah di isi dan kemudian untuk dihitung skor jawaban dari responden. Tahap terahir peneliti merekap semua data dan 
mengolanya. Serta untuk pengumpulan data sarana prasarana menggunakakan member check, dimana member check itu sendiri adalah suatu proses pengecekan data yang diperoleh peneliti kepada pemberi data atau diperoleh peneliti dari narasumber.

Instrumen merupakan alat bantu yang dipilih dan digunakan oleh peneliti agar kegiatan tersebut menjadi sistematis. Menurut Pujianto dan Insanistyo, (2013:61) instrumen penelitian adalah alat pengumpul data dalam suatu penelitian. Instrumen yang digunakan dalam penelitian ini adalah angket. Angket yang dimaksud adalah sejumlah pernyataan yang digunakan untuk memperoleh indormasi dari responden. Teknik analisis data penelitian ini menggunakan teknik statistik deskriftif kualitatif dengan metode survei yang menggunakan angket dengan presentase. Pada angket penelitian menggunakan skala likert dimana responden telah disediakan 4 alternatif jawaban.

\section{HASIL DAN PEMBAHASAN}

\section{HASIL}

a. Hasil Motivasi Latihan Atlet Provinsi Bengkulu Untuk Menuju PON XX Papua

Berdasarkan angket yang disebarkan secara Online dan ada juga yang secara tatap muka langsung responden, dengan pemberian 30 kuessioner maka diperoleh hasil dari analisis dapat dilihat pada tabel 5 sebagai berikut.

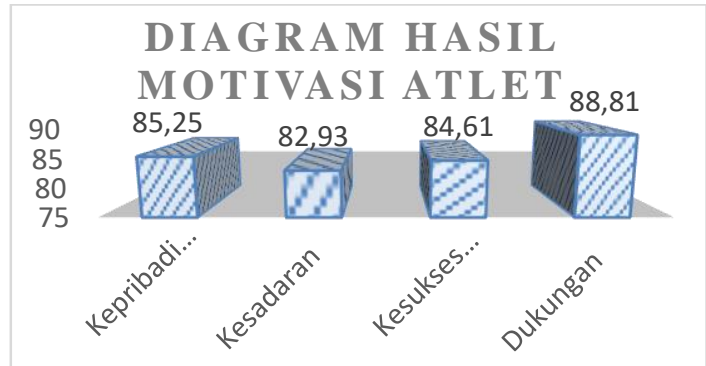

Gambar 1. Motivasi Latihan Atlet Provinsi Bengkulu Menuju PON XX Papua.

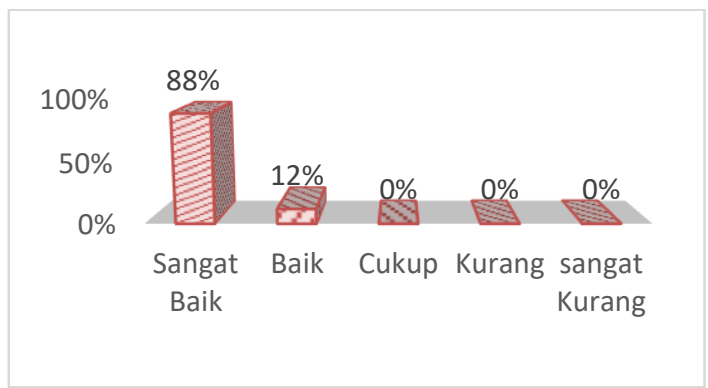

Gambar 2. Diagram Distribusi

Persentase Kepribadian Terhadap Motivasi Latihan Atlet

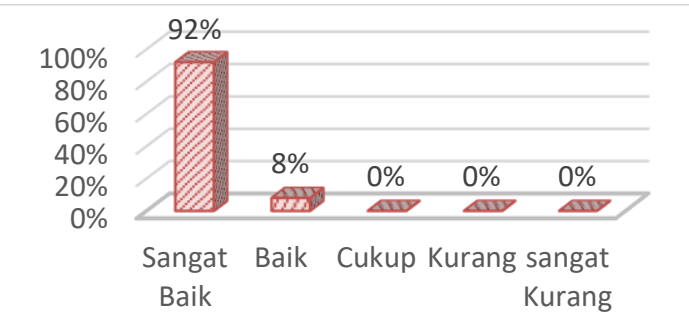

Gambar 3. Diagram Distribusi persentase kesadaran latihan atlet terhadapp motivasi latihan atlet

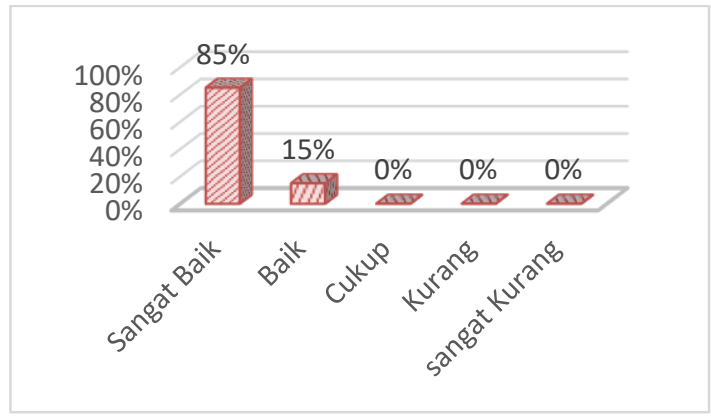

Gambar 4. Diagram Distribusi persentase tingkat kesuksesan dalam motivasi latihan atlet terhadapap motivasi latihan atlet 


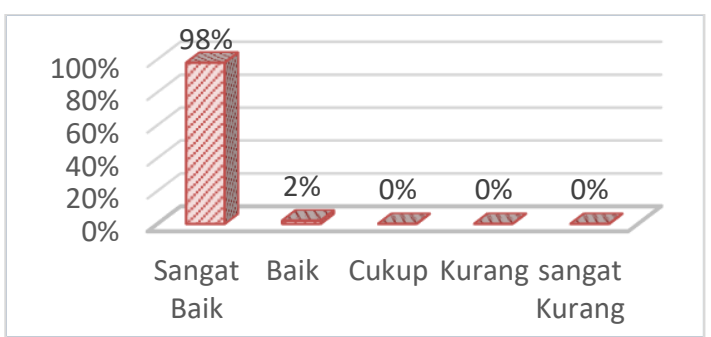

Gambar 5. Diagram distribusi persentase dukungan terhadapap motivasi latihan atlet

b. Hasil Member Check Sarana dan Prasarana Latihan Atlet Provinsi Bengkulu Menuju PON XX Papua

Hasil penelitian menunjukan persentase Member check pelatih untuk sarana dan prasarana latihan atlet Provinsi Bengkulu Menuju PON XX Papua menunjukan persentase per cabang olahraga, Sepak bola $60 \%$,voli $20 \%$, Bulu tangkis $80 \%$, Tenis Lapangan $70 \%$, Silat $80 \%$, Muaythai $50 \%$, Tinju $70 \%$, Gulat $80 \%$, Kempo $60 \%$, Panjat Tebing $100 \%$, Karate $80 \%$, Atletik 50\%, Renang 60\%, Billiard 50\%, Selam 70\%, PABBSI 70\%. Dengan pengkatagorian sarana dan prasaran latihan atlet untuk 1 cabang olahraga dengan katagori sangat baik sebesar $(6,25 \%)$, sedangkan 9 cabang olahraga dengan katagori baik sebesar $(56,25 \%)$, dan 6 cabang olahraga dengan katagori cukup sebesar $(37,5 \%)$. Sesuai yang dijelaskan sebelumnya bahwa berdasarkan hasil analisis data diketehui bahwa sarana dan prasarana latihan atlet adalah Baik.

Dari penjelasan di atas dapat dilihat hasil analisis data yang telah dilakukan serta kaitannya dengan permasalahan dan tujuan penelitian. Tujuan dari penelitian ini adalah umtuk mengetahui bagaimana sarana dan prasarana untuk persiapan latihan atlet menghadapi PON XX yang di selenggarakan di Provinsi Papua. Hasil analisis deskriptif menunjukan menunjukan bahwa sarana dan prasarana latihan atlet adalah baik. Hal ini terlihat dari hasil analisis data yang menunjukan sebagian subjek penelitian yaitu sebanyak 1 cabang olahraga $(6,25 \%)$ menunjukan sarana prasarana Latihan atlet untuk persiapan menuju PON XX yang di adakan di Papua sangat baik, sedangkan sebanyak 9 cabang olahraga $(56,25 \%)$ menunjukan bahwa sarana dan prasarana persiapn menuju PON XX Papua Baik, dan sebanyak 6 cabang olahraga $(37,5 \%)$ menunjukan bahwa sarana dan prasarana menuju PON XX Papua cukup untuk mempersiapkan atlet saat bertanding di Pekena Olahraga yang akan diselenggarakan di Provinsi Papua.

\section{PEMBAHASAN}

Berdasarkan hasil penelitian ini menunjukan bahwa Motivasi dan Sarana Prasarana Latihan atlet Provinsi Bengkulu Menuju PON XX Papua. Data penelitian berdasarkan pada hasil pengisian Kuessioner tentang Motivasi latihan atlet yang berjumlah 30 pernyataan untuk atlet dan 10 butir yang berbentuk member check untuk mengetahui bagaimana sarana dan prasarana yang diberikan kepada masing-masing pelatih cabang olahraga. Analisis data ini menggunakan teknik statistik deskriptif. Adapun teknik perhitungan menggunakan persentase yang dibuat dalam bentuk lima katagori yaitu: sangat baik, baik, cukup, kurang, dan sangat kurang. Pengkatagorian dibuat berdasarkan hasil perhitungan deskriptif yang telah dilakukan sebelumnya. 
Sesuai yang telah dijelaskan sebelumnya motivasi latihan atlet Provinsi Bengkulu menuju PON XX Papua sangat baik $(84,50 \%)$, di dalam motivasi atlet yang sangat baik terdapat dukungan dari beberapa aspek, dari orang tua, pelatih dan sarana prasarana latihan yang mendukung serta orangorang yang terdekat. Motivasi adalah energi psikologis yang bersifat abstrak dan wujudnya hanya dapat diamati dalam bentuk manifestasi tingkah laku yang ditampilkan individu. Dalam hubungan ini, motivasi sebagai proses psikologis merupakan refleksi kekuatan interaksi antara kognisi, pengalaman dan kebutuhan (Nopiyanto 2018). Motivasi juga bisa di artikan sebagai keterampilan mental yang bersifat mendasar yang perlu dimiliki oleh atlet. Jadi, yang dimaksud motivasi berolahraga dalam tulisan ini adalah tenaga pendorong untuk menampilkan sesuatu perilaku tertentu dalam olahraga dan merupakan refleksi kekuatan interaksi antara kognisi, pengalaman dan kebutuhan. menurut Komarudin (2016) "jika atlet memiliki kemauan kuat untuk sukses, 50 persen kesuksesan sudah di tangan".

Proses latihan akan berjalan dengan baik jika sarana prasarana mencukupi dan dari sarana prasarana latihan juga atlet bisa meningkatkan kemampuannya. Mulyasa dalam Purnama (2007: 185) menjelaskan tujuan pemanfaatan sarana dan prasarana adalah memberikan kontribusi yang optimal pada jalannya proses latihan atlet untuk mempersiapkan pertandingan PON XX Papua. Di samping itu, agar kegiatan latihan terlaksana dengan lancar dan efektif.

\section{PENUTUP SIMPULAN}

Berdasarkan hasil penelitian dan pembahasan yang telah diuraikan pada Bab sebelumnya, maka dapat disimpulkan hasil Motivasi Latihan Atlet Provinsi Bengkulu menuju PON XX Papua masuk dalam katagori sangat baik sebanyak $85,40 \%$. Sedangkan sarana dan prasarana latihan atlet dapat disimpulkan sebanyak 1 cabang olahraga $(6,25 \%)$ menunjukan sarana prasarana Latihan atlet dengan katagori sangat baik, sedangkan sebanyak 9 cabang olahraga $(56,25 \%)$ menunjukan bahwa sarana dan prasarana persiapan menuju PON XX Papua dengan katagori Baik, dan sebanyak 6 cabang olahraga $(37,5 \%)$ menunjukan bahwa sarana dan prasarana dengan katagori cukup untuk mempersiapkan atlet saat bertanding di Pekan Olahraga Nasional yang akan diselenggarakan di Provinsi Papua.

\section{SARAN}

Berdasarkan kesimpulan penelitian, saran yang dapat disampaikan yaitu:

1. Bagi Atlet khususnya atlet yang ada di Provinsi Bengkulu nantinya hasil dari penelitian ini dapat dijadikan evaluasi untuk atlet agar bisa meningkatkan motivasi latihan agar bisa menjadi atlet yang lebih professional.

2. Bagi pelatih agar bisa mengetahui seberapa besar motivasi atlet dalam persiapan menghadapi pertandingan. Pelatih juga bisa membuat program latihan untuk mengembangkan motivasi, mental, dan fisik atlet. Serta mengembangkan alat modifikasi penunjang latihan atlet. 
3. Bagi peneliti selanjutnya yang ingin melanjutkan penelitian ini dapat dijadikan sebagai bahan informasi dan referensi. Peneliti selanjutnya juga bisa membuat audio visual untuk meningkatkan motivasi atlet. untuk mendapatkan hasil yang lebih banyak lagi.

\section{DAFTAR PUSTAKA}

Arikunto, Suharsimi (2016) Prosedur Pendektan Praktik. Jakarta.

Assalam, D., \& Hidayah, T. (2015). Evaluasi Program Pembinaan Prestasi Cabang Olahraga Pencak Silat Pusat Pendidikan dan Latihan Olahraga Pelajar (PPLP) Provinsi Kalimantan Timur. Journal of Physical Education and Sports, 4(1).

Chan, F. R., \& Aziz, I. (2020). Motivasi Atlet Pencak Silat Pusat Pendidikan Latihan Pelajar (Pplp) Sumbar. Jurnal Patriot, 3(1), 120-128.

Fitantri, M. N. R. (2015). PENGARUH

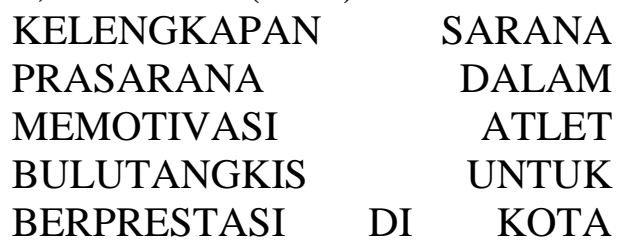

SALATIGA (Doctoral dissertation, Universitas Negeri Semarang).

Hidayat, R., Febriani, A. R., Budi, D. R., \& Listiandi, A. D. (2019). Pembinaan Prestasi Tim Sepak Takraw Putri Jawa Tengah Menuju PON XVIII Tahun 2012 di Riau. Jendela Olahraga, 4(2), 37-43.

Komarudin. (2016). Psikologi Olahraga Latihan Keterampilan Mental dalam Olahraga Kompetitif. Bandung: PT Remaja Rosdakarya.

Nopiyanto, Y. E., \& Dimyati, D. (2018). Karakteristik psikologis atlet Sea Games Indonesia ditinjau dari jenis cabang olahraga dan jenis kelamin. Jurnal

Keolahragaan, 6(1), 69-76.

Pujianto, Dian \& Insanistyo. (2013). Bahan Ajar Dasar-dasar Penelitian Pendidikan Jasmani. Bengkulu: FKIP Universitas Bengkulu.

Purnama, e. B., guntur, m. P., \& agus sumhendartin, s. (2007). Tingkat Kepuasan Atlet terhadap Sarana dan Prasarana Olahraga Tahun 2018/2019 di Pusat Pendidikan Latihan Olahraga Pelajar (PPLP) DIY.

Rumini, R. (2015). Manajemen Pembinaan Cabang Olahraga Atletik di Pusat Pendidikan dan Latihan Pelajar (PPLP) Provinsi Jawa Tengah. Journal of Physical Education Health and Sport, 2(1), 20-27. 